\title{
СТРУКТУРНО-СМЫСЛОВОЙ АНАЛИЗ МИФА О ГЛАМУРЕ НА ОСНОВЕ КОНЦЕПЦИИ СИМВОЛИЧЕСКИХ ФОРМ Э. КАССИРЕРА
}

Аннотация. Цель - исследовать современный миф о гламуре с точки зрения философии Э. Кассирера. Гламурный миф, как в челом всё мифическое, обладает тремя структурными компонентами - формой мысли, созерцания и жизни, раскрывающими его содержание. В гламурном мире эстетизируется бытие, в котором проявляются элементы сакрального, чудесного и божественного, способствующие бегству от реальности. Миф оказывается вечной символической формой, вмещающей в себя гламурные нарративы, делающие невозможными различение реального и вымышленного.

Обозначенная проблематика рассматривается на основе методов структурного, диалектического, символического и сравнительного анализа, помогающих раскрыть специфику современного модуса мифа, связанного с гламурным дискурсом.

В статье впервые осуществляется структурно-содержательный анализ мифа о гламуре, помогающий раскрыть его специфику. Выявлено, что традиционные законы мифотворчества (партиципации, метаморфоз, подобия, отождествления образа и вещи, антитезы сакрального и профанного) имеют место и в современности, приобретая гламурную модальность. Трёхчастная структура мифа, выделенная Э. Кассирером, позволяет проанализировать современные гламурные нарративы, в которых в качестве главных героев фигурируют архетипы античных богов.

Ключевые слова: гламур, миф, Э. Кассирер, форма мысли, форма созерцания, сакральное, профанное, форма жизни, театрализация, архетип.

Abstract. The goal of this article is to examine the modern myth about glamor from the perspective of Ernst Cassirer's philosophy. Glamorous myth along with all mythical as a whole, possess the three structural components - form of thought, contemplation, and life that reveals its content. It also aestheticizes the being, in which we can observe manifestation of the sacred, miraculous, and divine that encourages avoidance of reality. The myth becomes an eternal symbolic form, which encompasses glamorous narratives that makes it impossible to distinguish between the real and fictional. The author reveals that the traditional laws of mythopoeia (participation, metamorphose, similarity, identification of image and thing, antithesis of sacred and secular) are also present in modernity, acquiring glamorous modality. The three-part structure of a myth highlighted by E. Cassirer allows analyzing the contemporary glamorous narratives, in which the main characters are the archetypes of ancient gods.

Key words: form of life, secular, sacred, form of meditation, form of thought, Ernst Cassirer, myth, glamor, staging, archetype.

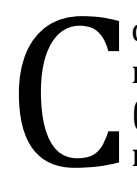

овременная гламурная идеология, рождающая новую форму языческой религии (пост)неоязычество, приводит к очередной волне интереса к мифотворчеству и всплеску мифизирования. Разновидностью мифического в современности является миф о гламуре и личные мифизирования внутри него, фиксирующиеся (устно/письменно/образно) в форме нарратива. Сам гламур обнаруживает тесную связь с мифическим: он олицетворяет совершенство, роскошный стиль жизни, внешний блеск и шик, что позволяет провести параллель с миром божественным.
Исследуя современные мифы о гламуре, обратимся к философии Э. Кассирера, представившим структурно-смысловую специфику мифа как форму мысли, созерцания и жизни [1]. Обращение к философии символических форм неокантианца неслучайно: Э. Кассирер посредством собственной методики раскрыл оригинальность мифа как структурированного логоса или космоса, структурирующегося в логосе (Ж.-Л. Нанси). Разработанное им структурное представление о мифе, как мы считаем, наиболее адекватно объясняет особенность современных гламурных мифов, опирающихся в 


\section{Философия и культура 8(104) • 2016}

своём содержании на мифологемы и клишированные формулы, делающие его текст одновременно предсказуемым и банальным, но в тоже время рождающим новые модификации, расширяющие мифологическое и семиотическое поля. Деконструкция современного мифического, в основе которой лежит кассиреровская методика, даёт возможность обнаружения «истины, сообщённой вымыслом» (Ж.-Л. Нанси).

В мифе как форме мысли, опирающемся на образы, обращённые к эмоциональной сфере личности, воспринимающей предложенное в качестве реального положения дел, осуществляется трансформация образа и сопутствующих ему эмоций в мысль. Ещё первобытные люди, понимая образную разницу вещей, в мифологической картине мира утверждали идею всеединства жизни, связывающей множество непохожих форм бытия. В современности содержание идеи всеединства искажается и/или игнорируется ввиду её устаревания и несоответствия индивидуализму эпохи, оставляя только внешнюю оболочку. В контексте гламура всеединство проявляется в приобщении к модным культурным/политическим/экологическим акциям/программам, различным практикам и тренингам. Внешне гламурные тактики позиционируют коллективизм, но внутренне - приобщение к ним обнажает эгоизм личности, манипулируемой консьюмеристской установкой «Вы - особенный!».

Гламурный миф как форма мысли базируется на определённых законах, связанных с мифотворчеством в целом. Одним из фундаментальных законов мифического является, по Л. Леви-Брюлю, закон партиципации, высвечивающий мистическую сопричастность всего в мироздании и имеющий несколько проявлений.

Во-первых, назовём закон метаморфоз - «всё может превратиться во всё», вытекающий из идеи всеединства и нерасчленённого взгляда на мир, в котором отсутствуют элементы теоретичности и научности. Подобный взгляд на мир впервые обнаруживает себя в первобытности, характеризуясь синкретичностью. Свою жизнь первобытный человек не мыслит, а ощущает и переживает как непрерывное целое, где не существует явных различений, поэтому границы между сферами оказываются размытыми. В силу этого (внезапно) любая вещь может превратиться в иную, являя собой чудо.

Одной из характеристик современного типа мышления, в том числе, в повседневных/экстремальных/кризисных ситуациях, является побег от рациональности, погружающий личность в пу- чину иррационального и бессознательного. Гламурное мифизирование, проникающее в различные сферы и формы культуры, уводит человека в мир чудес и иллюзий, воспринимаемый субъектом как реальность, по канонам которой он начинает строить свою жизнь. Мифологический глянцевый мир рекламы, сериалов, журналов, шоу-бизнеса воспринимается в качестве эталона, безоглядно и некритично. Сами герои современной культуры трактуются как небожители - Боги/Богини, которым поклоняются, подражая, реципиенты. Герой гламурного мифического в любой момент может осуществить метаморфозы: сменить имидж/внешность/биографическую историю, поведав об очередном событии своей жизни (нередко противоречащим всему предыдущему), тем самым являя чудо/чудесное. Тиражируемая жизнь героя воспринимается реципиентами в качестве своеобразного канона, выступая образцом для подражания и поводом для приобщения к гламурному. Именно копирование олицетворяет чудо в истории личности, что подводит нас ко второму ключевому закону мифологического мышления - закону подобия. В «Изумрудной скрижали» Гермес Трисмегист сформулировал его следующим образом: «как вверху, так и внизу», подразумевая под этим подобие и повторяемость устройств всех систем Вселенной [3, c. 21]. Суть закона в древности можно выразить следующим образом: человек - это микрокосмос, повторяющий устройство космоса. Перенося этот закон на современность, мы встречаемся с очередной трансформацией, где повторение связано с миром гламурного Олимпа, воспринимаемого в качестве социального образца. Подтверждение собственного подобия гламурному социальному осуществляется посредством зеркала как сакрального инструмента отражения. Взяв за образец мир глянца, обыватель начинает копировать его в имидже/стиле жизни и пр., постоянно заглядывая в зеркало и сверяя свою внешность с иконой стиля. В современности зеркальные поверхности повсюду окружают человека, буквально заставляя его любоваться собой, постоянно фиксируя свой образ посредством мобильных устройств и тиражируя его, в том числе, в социальных сетях.

В-третьих, важнейшим законом мифологического мышления является закон отождествления образа и вещи. Например, лицо, рекламирующее товар, становится его персонификацией, автоматически превращаясь в Бога/Богиню с собственной атрибутикой, приобщая реципиентов к божественности.

Отождествление образа и вещи приводит $\kappa$ значимости имён в гламурном социальном, где 
псевдонимы икон стиля и наименования брендов получают статус божественности. Дело в том, что имя в мифе не есть просто «функция изображения», а - воплощение божественной силы, аккумулирующей в себе жизненную энергию, способную оказать воздействие на всех соприкасающихся с гламурным. В современном обществе имена не только указывают на личность, но существуют и действуют сами по себе. В первую очередь, это касается собственных имён человека/вещи/фирмы. Неслучайно в современности человек, стремящийся попасть/по-nacmь в орбиту гламурного мира, меняет собственное имя на более звучное и благородное, потому что только необычное имя может принести бонусы и стать источником дохода, превратив личность в бренд, тем самым способствуя её гламурному статусу, карьерному росту, успешности, популярности и богатству.

Помимо этого, типичным для гламурного мифа отождествлением выступает портрет, выполняющий роль alter ego изображённого. В контексте гламура (фото-видео-) образы Богов/Богинь, с удовольствием позирующих перед камерами, заполняют всё пространство социального, что высвечивает желание оставить свой отретушированный портрет в веках, став легендой.

Рассматривая второе структурно-смысловое направление, представляющее миф как форму созерцания, выделим в нём закон антитезы сакрального и профанного: это - первое «удивление», порождающее явление мифа как культурного феномена. Согласно данному противопоставлению осуществляется интерпретация всего сущего, в том числе, времени и пространства. Различать границу сакрального и профанного может каждый человек. Так, в современности, благодаря тиражируемости гламурного, его пространственно-временные координаты оказываются узнаваемыми: на страницах глянца представлены (с элементами визуальности и художественности) описания гламурных мест (ресторанов/клубов/ бутиков/курортов и пр.) и лучшее время их посещения. Помимо этого, гламурное лицо в своих нарративах, сопровождающихся фото-видеосъемкой, фокусирует внимание реципиентов на точках его пребывания, становящихся сакрализованными, ввиду божественности персонажа. Все пространственные и временные координаты, связанные с гламуром, приобретают особую ауру привлекательности и соблазнительности, становясь местами паломничества.

Именно гламур, наделяя собственное время сакральностью, насыщает его особыми смысло- выми оттенками. Так, несмотря на историчность современности, в контексте гламура обнаруживается элемент неисторичности, обусловленный акцентом на красоте, молодости и богатстве: прошлое сегодня интенсивно стирается и/или полируется, подводясь под гламурно-развлекательный стандарт, примером чему выступает литература, кинематограф, живопись и пр. В пространстве гламурного искусства наблюдается бесконечное продуцирование эффектов, имеющий исторический флер, но не демонстрирующих истинную историю. Согласимся с Т. Адорно, утверждавшим, «когда история транспонируется в экзистенциал историчности, соль истории теряет вкус» [4, c. 129]. Современная гламурная историзация позиционирует определённую принадлежность истории, оказывающуюся при детальном анализе неисторичной.

Ещё один аспект гламурной неисторичности времени связан с потерей протяжённости: время превращается в вечное теперь, создавая иллюзию бесконечно длящейся красивой молодости, обладающей богатством. В вечном теперь «застыли» продолжаемые мифизированные истории молодящейся личности, чей возраст год от года не увеличивается. В контексте данной симулятивной реальности человек пытается реализовать собственный модус субъективности, постоянно изобретая истории, больше фантазийные и не имеющие ничего общего с действительностью. В итоге мы получаем многоликие нарративации, сосредоточенные на вечном теперь и, как правило, не имеющие продолжения, обрываясь в многоточиях. Наиболее ярко вечное теперь проявляется во внешности и проявлениях/про-явлениях гламурных персон. Постоянно подвергая своё лицо разного рода хирургическо-косметическим процедурам, они превращают его, в том числе, посредством грима и фотошопа, в маску с застывшим выражением. Данный персонаж, принимая участие в проектах/шоу/передачах, делая акцент на личностном аспекте, пускает в тираж мифизированнный нарратив о Я.

Помимо этого, гламурное время сиюминутно, оно пролетает так же быстро как сменяется актуальная тенденция/лицо/тема. Наиболее ярко мгновенность проявляется на «фабрике звёзд», штампующей звёзд одного дня/песни, и в моде, постоянно обновляющей стили, тенденции и лица. Неслучайно один из принципов гламурного социального звучит «модно быть модным», что подчёркивает эфемерность бытия и его подверженность метаморфозам, создающим иллюзию преображения личности в божественное и сакрально-гламурное. 


\section{Философия и культура 8(104) • 2016}

Третья структурно-смысловая сторона мифа как формы жизни связана с желанием перелицевать мир субъективных аффектов в чувственнообъективное бытие, рождая иллюзию воздействия на мир и приводя к театрализации человеком собственного $Я$.

Современный человек, живя в пространстве гламурного социального и следуя его образцам, начинает в реальной жизни играть себя-Другого. Театральная игра с бесконечной сменой ролей/ масок, укорененная в человеке, может длиться всю жизнь, позволяя разъединяться и соединиться с самим собой либо навсегда потерять свою Самость. При этом любая игра, в основе которой лежат мифизированные истории, являет собой спектакль/ представление/самопрезентирование, обладающее собственной формой и смыслом, нередко симулятивным. Как любая театральная сцена есть своеобразное открытое окно в воображаемо-игровой мир, где реципиентам представляется чужая жизнь, так и собственная мифизированная игра - сцена, на которой личность играет себя-Другого в главной роли. Сценарий для собственной пьесы жизни индивид пишет сам или его имиджмейкеры, внося в него постоянно те или иные поправки/коррективы в зависимости от обстоятельств. Человек каждый раз вживается в своё новое платье, меняя миро- и самоощущение, походку, манеру говорить и держаться в зависимости от надетого костюма, что способствует его метаморфозам.

Современная личная театрализация поддерживается огромным количеством праздников, где можно показать праздное Я. Сама «реальность гламура - это реальность непрекращающегося торжества», где «еда заменяется угощением, показ фильма - презентацией, одежда - дресс-кодом» [5, c.27]. Перечисленное, говорит в пользу карнавальности гламурного пространства, для которого характерна праздничность и переодевание как перелицевание, позволяя каждому увидеть иную сторону бытия и стать Другим, в чём обнаруживает себя привлекательные для личности магичность и волшебство.

Театрализация мифического тесно связана с ритуалом/культом, в контексте которых осуществляется жертва, обеспечивающая видимость мифическому. Форма приношения жертвенных даров в ритуале акцентирует идею обмена, вуалируя её (возможный) принудительный характер. В этом акте обмена «обоюдная потребность соединяет человека и бога и связывает их обоих, в равной степени и в одинаковом смысле: ибо бог зависит в этой ситуации от человека в той же мере, что и человек от бога. Всей своей мощью, более того, всем своим состоянием бог зависит от приношения совершающего жертву» [1, с. 234]. Приведённая цитата показательна для современности, где гламурный Бог/Богиня для поддержания рейтинга популярности нуждается в своих поклонниках, а те, в свою очередь, поклоняясь иконе стиля, выказывают собственную причастность к пространству гламура. Подобная диалектика взаимоотношений иллюстрирует суть жертвы - мотив почитания, придающий ей соответствующий, сакрализованный смысл.

В пространстве гламурного значимыми становятся жертвенные практики, связанные с разнообразными диетами, бесконечными косметическими/хирургическими процедурами, сопровождаемыми болевыми ощущениями, поклонением иконам стиля, точным следованием модным тенденциям, посещениями культовых мест и общением с гламурными лицами, на которые тратится огромное количество энергии, времени и денег. Как правило, перечисленное является тщетным, хотя и высвечивает личную жертву, связанную с почитаемым отношением к чему-либо гламурному.

Ещё одним аспектом мифа как формы жизни можно назвать - мана, относящийся к разряду труднопостижимых феноменов. Мана - это нечто действенное, могущественное и одухотворённое, присутствующее в конкретной жизни как запас магических сил. М.Элиаде трактует феномен в качестве рассредоточенной мистической силы, способной принимать любую форму жизни: она в равной степени приписывается простым вещам, отдельным лицам, одушевлённому и неодушевлённому. Считается, что вещи и люди, получив мана от божественных сил, становятся причастными к сакральному. «Если обнаруживается, что в камне заключена сверхъестественная сила, это потому, что с ним связан некий дух; кость умершего обладает мана, ибо в ней присутствует дух этого умершего; человек может быть столь тесно связан с природным духом или духом умершего, что сам становится носителем мана и может направлять её на исполнение своих желаний» [6, с. 34].

Мана, качественно отличаясь от физических сил, функционирует довольно произвольно. Её действие проявляет себя во всём, что обладает превосходной степенью, являясь совершенным, действенно-динамичным и плодотворным. Например, мана есть в амулете воина-победителя, быстроходной лодке, рыбной сети с огромным уловом, плодоносном саду, стреле, убивающей врага. Перечисленные примеры показывают, что благодаря иерофании как «священному, предстающему 
перед нами» [7, с. 13] объект отличается своей экстраординарностью, необычностью, выдающимися талантами.

Перенося понимание мана на современность, обнаруживаем его связь с гламуром: мана предстаёт в пространстве современного социального как флер гламурного. Обращение к французскому слову flers, как мы считаем, является обоснованным. Среди его значений - «покров таинственности»/«дымка, скрывающая чтолибо», явно указывающие на мана гламура. Например, в современности всё гламурное изначально обладает мана/флером, распространяющим своё энергийное воздействие на окружающий мир. Мана гламура является мощным оберегом/ талисманом, своеобразным пропуском в особый мифизированный мир - мир красоты, молодости и богатства. Лицо, обладающее гламурным мана, проходит любой face control: двери перед ним, как по взмаху волшебной палочки, магически раскрываются. Гламурное лицо, посетившее определённое место/дотронувшееся до вещи, тут же наделяет их своей магической силой, возводя в статус гламурности, тем самым сакрализируя их. Мана гламурной вещи связана, не в последнюю очередь, и с её созданием. Так, роскошный предмет класcа luxury приобретает мана при изготовлении - «в соответствии с тайными, тщательно охраняемыми рецептами» из особых материалов [5, с. 38], некоторые из которых ввиду редкости/труднодоступности/малочисленности усиливают его волшебную силу.

Разработанная Э. Кассирером методика структурно-смыслового анализа мифа не потеряла своей актуальности и в современности, позволяя разобрать гламурные нарративы, главные роли в которых принадлежат, как мы считаем, архетипичным персонажам.

Обращение к архетипам обусловлено рядом обстоятельств. Ещё 3. Фрейд, проанализировав эдипов комплекс, пришёл к идее о связи греческой мифологии и психики человека. Термин архетип впервые появляется в концепции психоаналитика К.-Г. Юнга, под которым он понимал врождённые психические структуры и образы фантазии, присущие человеческой общности и составляющие основу коллективного бессознательного. До сих пор нет полного систематизированного списка архетипов. Сам К.-Г. Юнг, работая с архетипами, постепенно пополнял свой список, когда возникала необходимость. Концепция архетипов была продолжена огромным количеством исследователей. Среди них назовём Д.Ш. Болен, которая, проанализировав архетипичность Богинь/
Богов в каждом человеке, продемонстрировала положительные/сильные и отрицательные/ слабые черты метафизики личности [8; 9]. Как замечает психоаналитик, «боги обуславливают эмоциональную открытость или замкнутость; склонность к умственной деятельности, физической работе или эстетической чувствительности; стремление к экстатическому слиянию с миром или его умопостижению; отношение к времени и многое другое» [9, с. 16].

В нашем контексте выделим архетипы популярных античных богов, копии которых обнаруживаются в гламурном социальном при мифизировании Я: Зевс, Аполлон, Гермес, Дионис и Афродита. Так, Зевс, символизируя верховную власть, величие и первенство, рождающие амбициозность и самовлюблённость, несёт с собой беспощадность и разрушения. Он способен к бесконечным метаморфозам, благодаря которым, перевоплощаясь, достигает любой желаемой цели, в том числе связанной с покорением женских сердец (форма мысли). На вершине Олимпа Зевс, сакрализируя собственное пространство/время/деяния, внушает окружающим свою божественность (форма созерцания). Обладая мана власти/богатства, виртуозно ими пользуясь и выставляя напоказ, Зевс требует поклонения себе, в том числе, в виде обязательного чествования на всевозможных праздниках и торжествах (форма жизни). Аполлон, олицетворяя красоту, гармонию и эмоциональную холодность, проявляющиеся в высокомерии и отсутствии привязанностей во взаимоотношениях, также способен к метаморфозам своего образа, но при этом он не забывает о принципе «знай меру». Во всём совершаемом им высвечивается любовь к ясности и чёткой конструкции (форма мысли). Умение ставить цели, мчаться к ним на большой скорости, чему способствует модус современной идентичности - электронное кочевничество, и добиваться поставленного, приводит к их сакрализации (форма созерцания). Его мана связана с креативной составляющей, позволяющей проявиться в искусстве, в том числе, искусстве гламурно жить (форма жизни). Архетип Гермеса, любимчика Фортуны, являет собой гламурного трикстера - вестника и хитреца, способного вывернуться в любой ситуации, избегая наказаний. Находясь постоянно в движении, он быстро схватывает идеи и реализует их благодаря дружелюбию, красноречию и связям. Но при этом к особым привязанностям в социальном он не стремится, потому что его жизненное кредо «то здесь, то там» (форма мысли). Коммуникативные способности Гермеса позволяют без высокомерия переходить из сакрального пространства в 


\section{Философия и культура 8(104) • 2016}

профанное и наоборот, что говорит в пользу лиминальности (форма созерцания). Особую жизненную энергию ему дают творческие и разного рода алхимические практики, помогающие ему использовать любые попадающиеся на пути возможности. Более того, благодаря легкомысленному отношению к происходящему и умению жить ритмами современности/со-временности Гермес остаётся вечно молодым (форма жизни). Дионис воплощает страстную и экстатичную натуру, быстро погружающуюся в мир чувственности и предпочитающую жить этими мгновениями, нередко на грани безумия и типичного гламурного кошмара/ужаса. Данный образ жизни влечёт подверженность чревоугодию и алкогольному/наркотическому опьянению, что способствует образным метаморфозам (форма мысли). Опекаемый окружающими, в том числе - матерью, Дионис ведёт праздный образ жизни, размывающий границы профанного и сакрального, что формирует искаженное само- и мировосприятие (форма созерцания). Дионисийская мана проявляется во время торжеств, которыми он, предпочитая праздный образ жизни, любит управлять, демонстрируя свою страстную натуру (форма жизни).

Среди женских гламурных архетипов назовём Афродиту, выступающую в качестве символа любви и красоты. Её форма мысли связана с умением, перевоплощаясь, обольщать, всегда оставаясь объектом желания. Другое дело, что Афродита, олицетворяющая чувственность и желанность, оказывается неразборчивой в своих связях, не желая задумываться о серьёзности некоторых последствий. Искусство флирта позволяет Афродите влюблять в себя всех окружающих мужчин, превращая в арену любви любое пространство, снимая границы сакрального и профанного (форма созерцания). Именно мана любви, стимулирующая творческого начало и театрализацию Я, делает её повелительницей мужских сердец, готовых выполнять все её капризы и прихоти. Афродита ради поддержания гламурного имиджа пойдёт на любые жертвы, связанные с поддержанием красоты и молодости (форма жизни).

В заключении подчеркнём следующие моменты. Анализ современного социального позволяет обнаружить огромное количество мифов, заставляя утверждать, что мифотворчество оказывается созвучным гламурному. Дело в том, что миф, обладающий внутренней прочностью и плотностью, представляет собой вечную символическую форму, способную трансформироваться, подстраиваясь к различным изменениям, тем самым являя своей онтологией закон устойчивости.
Современный миф о гламуре обладает, обозначенной Э. Кассирером, структурно-смысловой спецификой мифического в целом. Его можно проанализировать в трёх направлениях - как форму мысли, созерцания и жизни, что помогает выявить особенности гламурного и обнаружить его симуляции, подвергнув критике.

С одной стороны, появление современного мифа о гламуре помогает эстетизировать окружающую действительность, заимствующей из мифического элементы сакрального, чудесного и божественного. Сегодня каждый человек предпринимает попытки художественно обработать себя, чтобы быть современным. Но, с другой стороны, люди в пространстве гламурного перестают различать реальное и вымышленное, смешивают профанное и сакральное. В итоге в жизнь внедряются мифизированные черты вечного теперь, осуществляется театрализация Я, приносятся бесполезные жертвы преходящему.

Безусловно, избежать мифического в контексте социального невозможно, потому что миф как вечная символическая форма благодаря божественному и празднично-фантазийному помогает личности преодолевать негативное в виде абсурда/отчуждения/конфликтов. Другое дело, что в мифе о гламуре необходимо расставить иные акценты. Во-первых, различение фантазийного и реального поможет личности удержаться на орбите действительности, структурируя пространственно-временные границы проявления каждого из них. При этом перевес должен быть на стороне феноменологической действительности, а не наоборот, как в гламурном социальном, - на стороне мифизированного.

Личности необходимо понять, что красота, молодость, богатство и разного рода их мифизации - константы временные/непостоянные, их нельзя бесконечно симулировать. Событийствование/ со-бытийствование согласно личным ритмам и жизненным циклам, не исключающим уродства, старости и бедности, представляет собой искусство, в том числе, искусство жить в конфликте с собой/окружающими, чему необходимо научиться, минуя/(подключая) мифическое как элемент.

Еще одним способом, помогающим структурировать Я, ограждая от гламурного мифического, являются метафизические эпизоды интеллектуальной тишины, связанные с погружением в-себя, помогая быть $c$-собой и осуществляя разумное бытие для-себя. Они ориентируют личность на поиск смысла жизни, намечая в ней краткосрочные/долгосрочные свершения/достижения в социальном и для социального. 


\section{Список литературы:}

1. Кассирер Э. Философия символических форм. М.-СПб.: Университетская книга, 2002. Т. 2. 280 с.

2. Нанси Ж.-Л. Непроизводимое сообщество. М.: Водолей, 2011. 208 с.

3. Изумрудная скрижаль / Текст, перевод и комментарии К. Богуцкого // Гермес Трисмегист и герметическая традиция Востока и Запада. Киев: Ирис; М.: Алетейа, 1998. 623 с.

4. Адорно Т. Негативная диалектика. М.: Научный мир, 2003. 374 с.

5. Осиновская И. Поэтика моды. М.: НЛО, 2016. 144 с.

6. Элиаде М. Очерки сравнительного религиоведения. М., 1999. 488 с.

7. Элиаде М. Священное и мирское. М.: Изд-во МГУ, 1994. 144 с.

8. Болен Д.Ш. Богини в каждой женщине. Новая психология женщины. Архетипы богинь. М.: София, 2005. 272 с.

9. Болен Д.Ш. Боги в каждом мужчине. Архетипы, управляющие жизнью мужчин. М.: София, 2008. 400 с.

\section{References (transliterated):}

1. $\quad$ Kassirer E. Filosofiya simvolicheskikh form. M.-SPb.: Universitetskaya kniga, 2002. T. 2. 280 s.

2. Nansi Zh.-L. Neproizvodimoe soobshchestvo. M.: Vodolei, 2011. 208 s.

3. Izumrudnaya skrizhal'. Tekst, perevod i kommentarii K. Bogutskogo // Germes Trismegist i germeticheskaya traditsiya Vostoka i Zapada. Kiev: Iris; M.: Aleteia, 1998. 623 s.

4. $\quad$ Adorno T. Negativnaya dialektika. M.: Nauchnyi mir, 2003. 374 s.

5. $\quad$ Osinovskaya I. Poetika mody. M.: NLO, 2016.144 s.

6. Eliade M. Ocherki sravnitel'nogo religiovedeniya. M., 1999. $488 \mathrm{~s}$.

7. Eliade M. Svyashchennoe i mirskoe. M.: Izd-vo MGU, 1994. 144 s.

8. Bolen D.Sh. Bogini v kazhdoi zhenshchine. Novaya psikhologiya zhenshchiny. Arkhetipy bogin'. M.: Sofiya, 2005.272 s.

9. Bolen D.Sh. Bogi v kazhdom muzhchine. Arkhetipy, upravlyayushchie zhizn'yu muzhchin. M.: Sofiya, 2008.400 s. 